
\title{
25 Research Square \\ Exploring The New Rehabilitation Model of Hearing Impaired Children from the Perspective of Family
}

\author{
Mengxiao Yu \\ Wenzhou Medical University \\ Haixia Xie ( $\nabla$ xhx1020@wmu.edu.cn ) \\ Wenzhou Medical University \\ Qiwen Chen \\ Wenzhou Medical University \\ Shengnan Yao \\ Wenzhou Medical University
}

\section{Research Article}

Keywords: children, rehabilitation, parents, hearing, impaired, family, factors, study, role

Posted Date: July 14th, 2021

DOl: https://doi.org/10.21203/rs.3.rs-602748/v1

License: (c) (1) This work is licensed under a Creative Commons Attribution 4.0 International License. Read Full License 


\section{Abstract}

The primary aim of the study was to obtain the views of parents on the role of family efficacy in children's rehabilitation stage through investigation. The secondary objective was to evaluate the important role of family factors in the rehabilitation of hearing-impaired children. The third objective was to explore the willingness of parents to accept online courses, parents' Union and personalized family therapy.This study included 480 parents of hearing-impaired children. The questionnaire was distributed and collected in December 2020. And the parents of hearing-impaired children in the stage of postoperative rehabilitation were selected as the research objects.Although the rehabilitation process of hearingimpaired children is affected by many factors, family factors play a dominant role. In the rehabilitation process of hearing-impaired children, parents need to spend a lot of money, time and energy. At the same time, for the effect of rehabilitation, most parents tend to ignore the mental health rehabilitation of hearing-impaired children, only pay attention to the rehabilitation of speech clarity, hearing ability, communication ability of children. Moreover, parents generally believe that the function of the family is mainly responsible for the children's daily life, and only a few families are responsible for the language rehabilitation and mental health of hearing-impaired children. Therefore, parents' understanding of family efficacy is not comprehensive enough. And through the survey, we can see that from the perspective of parents, parents' lack of professional knowledge, lack of self-confidence and time factors will affect children's rehabilitation process. For the measures we proposed, such as online courses, parents' Union, personalized family therapy mode, parents of hearing-impaired children generally have a high acceptance. It can be seen that these measures can promote family efficacy and improve the rehabilitation effect of hearing-impaired children to a certain extent.The rehabilitation of hearing-impaired children needs to extend from schools and rehabilitation institutions to families to form a more unified and comprehensive rehabilitation system,especially on children's psychological rehabilitation. The corresponding models and Countermeasures of hearing-impaired children's family participation in China are extremely insufficient.Based on this, this study puts forward hypothetical Countermeasures in the form of questionnaire, investigates the recognition of parents, explores the innovation of family participation mode of hearing-impaired children, and puts forward accurate countermeasures.

\section{Introduction}

Hearing loss in children is common and by age 18 years, affects nearly 1 of every 5 children ${ }^{1}$.Alexandra Dezani Soares' research shows that hearing-impaired children have abnormalities in different aspects of language, involving form,content and use, in relation to their normal-hearing peers ${ }^{2}$. Therefore,hearing rehabilitation is important, without it, hearing loss can cause detrimental effects on speech, language, developmental, educational, and cognitive outcomes in children ${ }^{1}$. Hearing aids and cochlear implants have been widely used in the treatment of hearing-impaired children, but the rehabilitation effect of hearing-impaired children is not ideal. Lizet ketelaar's research shows that cochlear implantation can not restore normal hearing, and the effect of language training is limited ${ }^{3}$. In a broad sense, the rehabilitation of hearing-impaired children represents a comprehensive rehabilitation, which contains both physical and 
psychological aspects. Impairment of hearing is a common birth defect which may be associated with varieties of psychological abnormalities in childhood ${ }^{4}$. The detection rate of mental health problems of hearing-impaired children is significantly higher than that of normal children. There are many effects on the rehabilitation of hearing-impaired children. After the investigation and research of our team, we will mainly start from the perspective of family.Many researchers have put forward the importance of family in the process of investigation and research. For example,Stein etal's investigation shows that in addition to correct medical evaluation and timely training, the importance of family training can not be ignored $^{5}$.But a pratical plan does not been come up.Based on the Satya (family combination therapy) model $^{6}$, our team will provide a set of feasible programs for the family rehabilitation training of hearingimpaired children. Parents with insufficient reserve of rehabilitation knowledge can learn on demand through parents' school. Facing the special problems of different families, our experts will solve them pertinently. Lisa Furlong identified 14 studies and evaluated a total of 11 computer-based speech therapy programs. The results showed that computer-based speech therapy is associated with positive clinical changes for some children with speech sound disorders ${ }^{7}$. Therefore, we will use the convenience and full coverage of today's Internet to launch publicity in the form of short videos and rehabilitation training apps. In the later stage, we will scientifically monitor and evaluate the rehabilitation effect of hearingimpaired children by means of speech recognition and mouth image recognition, referring to the language rehabilitation level curve of children with hearing impairment. Then, through the mode of strengthening training of weak links, the pronunciation level of hearing-impaired children at all stages is restored to the expected level ${ }^{8}$. Through the combination of universality and personalization, we will activate family efficacy more effectively and promote the comprehensive physical and psychological rehabilitation of hearing-impaired children.

\section{Methods}

The study was performed in accordance with relevant guidelines and regulations. The study was approved by the Medical Ethics Committee of the Wenzhou Medical University Health and Bioethics Center. Participants were informed about the study rationale and procedures; written informed consent was obtained from all participants. All methods were carried out in accordance with the relevant guidelines and regulations.

\section{Questionnaire}

Before the group study, we conducted a questionnaire survey on the parents of hearing-impaired children to evaluate the importance of family efficacy in children's rehabilitation stage, and to count the willingness of parents for personalized family therapy. 480 parents of hearing-impaired children were asked to fill in questionnaires through rehabilitation center and online. Then statistical knowledge was used for data analysis, so as to understand the parents' understanding and needs of hearing-impaired children for family combined therapy, as well as to provide basis for the future work of the group. After full publicity and introduction, we will count the willingness of parents for this model through the scale. 
Subjects

In 2020, this study identified 48 hearing-impaired children and invited the parents of 48 hearing-impaired children in Zhejiang Province to participate. All hearing-impaired children received rehabilitation treatment in hearing rehabilitation institutions. The duration of rehabilitation treatment for hearing-impaired children varies.

Procedure

With the consent of the parents, the questionnaire was sent to the parents of the hearing-impaired children. Through the questionnaire, we can get the questionnaire including the basic information of parents. In addition to these data, we can also understand the ideas of parents of hearing-impaired children from the content of the questionnaire, and master the level of family function.

\section{Statistical analysis}

Through online and offline questionnaires, we understand the parents' views on the rehabilitation of hearing-impaired children. After the field visit to rehabilitation institutions for hearing-impaired children, we will conduct a comprehensive analysis of the effectiveness based on the statistics of the data, and then summarize, process and analyze the data, so as to increase the scientificity of practical research and avoid the loopholes caused by subjective factors as far as possible.

\section{Result}

\section{Response Rate}

We distributed questionnaires through online platform and visited rehabilitation institutions for hearingimpaired children. A total of 480 parents of hearing-impaired children participated in this study, including 173 males and 307 females, accounting for $37.5 \%$ and $62.5 \%$ respectively (Fig. 1 ). The gender ratio (100 females, male to female ratio) was 60 . The gender ratio of parents is in line with the social status that mothers spend more time with their children than fathers in families with special children.

Gross(1995) and his colleagues conducted a survey in the form of questionnaire in an institution that provides early intervention for children with autism. The results showed that only 40 percent of the 132 pairs of parents had participated in the intervention, either alone or with their wives, and that half of the fathers who had participated in the intervention had a pre-class absence, a rare occurrence among mothers. At the end of each intervention, parents were assigned a task at home to complete and write down their feedback. Only $30 \%$ of fathers successfully completed the homework, while $100 \%$ of mothers completed it ${ }^{9}$. Parents' educational level, occupation and income are various, so our research is random and reliable. We received 480 valid answers, accounting for $100 \%$. And the questionnaire will be returned in December 2020. 


\section{Family Expenses}

The rehabilitation of hearing-impaired children needs a large and sustained economic investment. We learned from the survey that more than $90 \%$ of the parents said that they spent more than 10,000 yuan on the treatment and rehabilitation of their children, while nearly half of the parents spent more than 10,0000 yuan on the rehabilitation of their children (Fig. 2). The rehabilitation of hearing-impaired children is a long and arduous process. In order to pursue a good and effective rehabilitation effect, families need to spend a lot of energy and financial resources.

The important of family factors

Based on the investigation of 480 parents of hearing-impaired children, we found that most of them regards family factors(including family atmosphere and economic burden) as the main factor affecting the rehabilitation of hearing-impaired children among other factors, including medical and health level, social factors (including social integration and public awareness) and institutional factors (including rehabilitation subsidies, welfare policies, etc.) (Fig. 3). Family factors are the Family supports everyone's growth, and it plays an indispensable role in special groups such as hearing-impaired children. This survey shows that although the rehabilitation of hearing-impaired children is affected by a number of factors, family factors play a leading role.

\section{Chart analysis}

Analyse1: The rehabilitation treatment of hearing-impaired children should involve many aspects, including speech clarity, hearing ability, communication ability, mental health, etc. Based on this, we conducted a questionnaire to 480 parents of hearing-impaired children (Fig. 4). From the data, it is not difficult to find that in the view of parents, the main evaluation indicators of hearing-impaired children's rehabilitation are speech clarity, hearing ability and communication ability. They are the direct basis to reflect the rehabilitation situation, but in fact, the mental health of hearing-impaired children is also included in the rehabilitation situation, which can not be ignored. Only when physical health and mental health are recovered at the same time can the rehabilitation of hearing-impaired children be improved. It can be seen from the chart that few parents attach importance to the rehabilitation of hearing-impaired children's mental health. Therefore, parents should pay more attention to the development of hearingimpaired children's mental health.

Analyse2: We have investigated the view of parents on what the family should be responsible for their children (Fig. 5). Among them, parents generally believe that the family is mainly responsible for the children's daily life (accounting for 100\%), and a small number of families are responsible for the language rehabilitation (43.75\%) and mental health (22.92\%) of hearing-impaired children. Therefore, parents' understanding of family efficacy is not comprehensive enough. For hearing-impaired children, language rehabilitation and mental health are two important aspects of family responsibility. Families should not only meet their children's material needs and take care of their daily life, but also care for their language rehabilitation and mental health. Family is the cradle of children's healthy growth, which 
determines that family should give full play to its effectiveness and accelerate the rehabilitation process of hearing-impaired children. So far, the data are objective, and the family efficacy has not been brought into full play. Therefore, we should strengthen the concept and consciousness of parents, guiding them to play the family function and role efficiently.

Analyse3: In order to better understand the obstacles that families of hearing-impaired children encounter when taking family rehabilitation measures, we conducted a survey on the 480 parents of hearingimpaired children (Fig. 6). According to the data, from the perspective of parents, lack of rehabilitation professional knowledge, lack of self-confidence and time factors ranked first, second and third among the obstacles parents met. The lack of professional knowledge and professional skills will greatly reduce the effect and speed of rehabilitation of hearing-impaired children, and parents will become confused and helpless in the face of children's rehabilitation. The lack of self-confidence in the process will not only lead to the lack of goals and motivation, but also affect the social ability of parents, make them lose the consciousness and courage to integrate into the community, and even affect their mental health. In addition, parents' lack of time and energy to take care of their children will also become an important obstacle in the rehabilitation process of hearing-impaired children. Children's rehabilitation training is difficult to complete independently, which is bound to need parents' supervision and accompany. Without the time to accompany them, the effect of rehabilitation training will be greatly reduced. Besides, children's resistance and financial support are also important obstacles in the process. Children's resistance directly affects children's acceptance of rehabilitation training, thus affecting the rehabilitation effect. At the same time, there is no solid economic foundation the rehabilitation training process will be hindered. It can be seen that parents will encounter various obstacles in the rehabilitation process of hearing-impaired children. As far as possible to help parents of hearing-impaired children to solve such difficulties has become a social hot spot.

\section{Acceptance Of Measures}

According to the rehabilitation needs of hearing-impaired children and parents' wishes, we put forward the following measures. First of all, we will provide cost-effective online courses, so that parents can get more rehabilitation knowledge reserves and master more useful skills with less cost. Additionally, we propose the method of parents Union. The communication between parents can be used as an effective way to relieve parents' psychological pressure, so as to achieve the goal of venting pressure, getting encouragement and help, then, parents will improve social participation and promote interpersonal communication. Less communication between parents is not conducive to parents sharing rehabilitation experience, thus reducing the rehabilitation efficiency of hearing-impaired children. Parents' Union will be a useful platform for parents with common experience to have empathy and common topics. At the same time, it can also make their children establish a deeper friendship with other children in the rehabilitation center in the future. Besides, we will also propose personalized rehabilitation programs. Personalized family rehabilitation program can help hearing-impaired children recover more targeted and accurately, improve the rehabilitation effect and efficiency, cultivate the ability of hearing-impaired children, and shape a good character. The programs can also reduce the psychological burden of families, make them 
full of confidence and hope for the rehabilitation of children, form positive feedback, promote the rehabilitation of hearing-impaired children with a positive and optimistic attitude, and improve the overall quality of life of families. The survey found that most parents have a high degree of acceptance of the above measures. These measures also have bright prospects.

\section{Discussion}

This study aimed to identify the effect of family factors on hearing-impaired children's rehabilitation in Physical and psychological. It is widely accepted that the rehabilitation of hearing-impaired children is greatly influenced by family factors. However, Current situation of family rehabilitation is unclear and literature in this area is scarce. The present study complements the findings of previous research and provides a deeper understanding of Comprehensive rehabilitation by exploring the experiences of 48 adults who parent a child with hearing impairment.

Lizet Ketelaar have demonstrated that cochlear implantation does not ensure good rehabilitation and optimal oral development. Although cochlear implants enable speech perception to a certain extent in children with severe hearing impairment, they do not restore normal hearing, and the effectiveness of speech training is limited ${ }^{3}$.

The Language rehabilitation training of hearing-impaired children including Oral and written form. In the process of learning, hearing impaired children often have problems such as poor vocabulary, difficulty in making sentences, inaccurate pronunciation, difficulty in understanding, and inability to actively communicate with teachers due to their own functional impairment and developmental disorder, and they need to be very attentive listening and observation. Distraction and lose interest, initiative, and even disgusted, leading to poor recovery effect, poor speech function.

In the last decade or so, auditory-verbal therapy(AVT) has been widely promoted. AVT is a listening and spoken language (LSL) instructional approach. The AG Bell Academy for Listening and Spoken Language provides certification to specialists who deal with $\mathrm{HL}$ children ${ }^{10}$.Therefore, for caregivers who would like their HL children to develop speech, AVT can be seen as a reliable solution ${ }^{11}$. This method requires hearing impaired children to use their hearing to learn oral communication, and attaches great importance to the close cooperation between visual and hearing teachers, hearing and speaking teachers and parents of hearing impaired children, especially emphasizing the deep involvement of parents, and guiding and training parents to become the primary promoters of hearing impaired children's oral development. However, its problems are also prominent, mainly reflected in the small number of practical research topics on auditory oral method and narrow scope. For example, the problems involved in the research on the application of auditory oral method are still focused on the one-way teaching and guidance of professionals for hearing-impaired children and families. AVT can be seen as a tool for $\mathrm{Cl}$ children to catch up with their $\mathrm{NH}$ peers, but future studies need to clarify many weaknesses in the process of evidence and validity ${ }^{12}$. 
There are still few studies on how to take family as the center, based on family cultural differences, advantages of community resources and other issues to discuss how to help families improve rehabilitation effectiveness. At the same time, research results on the effectiveness of auditory and spoken language are mainly based on theoretical and empirical description, and there is a lack of welldesigned, objective and credible research projects and research topics to track the effectiveness of children's comprehensive rehabilitation.

Rehabilitation of hearing impaired children, in a narrow sense, is to make full use of various means and methods to treat hearing and language problems of hearing impaired children in targeted ways, so that they can perceive the outside world and regain the ability to communicate. In a broad sense, the rehabilitation of hearing-impaired children represents a comprehensive rehabilitation, which contains both physiological and psychological.

In the past, the society paid more attention to the speech and hearing recovery of the hearing-impaired children. Lizet Ketelaar wrote in her article,"Currently, most children with a severe to profound hearing loss $(\mathrm{HL})$ in the Western world receive a cochlear implant $(\mathrm{Cl})$. This device electrically stimulates the auditory nerve, bypassing the damaged part of the ear. The positive effects of this technology are undisputable. Numerous studies have shown that cochlear implantation improves auditory and language skills in the majority of children with a severe to profound HL. In comparison, few studies have been dedicated to examining children's social-emotional development after cochlear implantation ${ }^{3}$."

A person's psychological state is also crucial to his personal development. Generally, the mental health level of hearing-impaired children is significantly lower than that of ordinary children, and some hearingimpaired children may even have inferiority and autism psychology. Lizet Ketelaar's research implies that children with a $\mathrm{Cl}$ are at higher risk for experiencing social-emotional difficulties. A recent review of studies conducted among children with hearing impairment convincingly showed that there was a link between hearing disability and Psychological status. Emotional behavior disorder may be associated with poor Presentation ability.

The physical rehabilitation of hearing impaired children is poor, and the level of hearing recovery and speech acquisition is low. This will affect the mental rehabilitation of hearing-impaired children. Similarly, psychological problems limit optimal physical recovery.

Therefore, we will pay attention to the hearing-impaired children from both physiological and psychological aspects to promote their comprehensive recovery. This is not the same as the rehabilitation of hearing-impaired children in the narrow sense, but it is of great significance and has an impact on the development of hearing-impaired children in their later life.

Parents play an important and irreplaceable role during the rehabilitation of hearing-impaired children, so it is very important for the parents to receive appropriate training. The degree of parental cooperation can affect the time of hearing impaired children's speech training, and the positive cooperative attitude of 
parents will improve the effect of children's speech rehabilitation. Hearing-impaired children's chances of integrating into hearing society largely depend on their parents ${ }^{13}$.

Ennur Erbasi, Nerina Scarinci, Louise Hickson, et al conducted a study about Parental involvement in the care and intervention of children with hearing loss. The results indicated that parental involvement in the intervention of children with hearing loss is multifaceted in nature and incorporates a broad range of behaviours and practices ${ }^{14}$.

Children have the most contact with parents every day, and their development is more directly dependent on the guidance and feedback of parents, and the most important growth environment is the family. Therefore, we study whether family factors are related to the formation of children's hearing and language ability, and whether they affect their overall recovery and social integration mentality and emotional cognition. Concretely analyze the factors of family details and explore the influencing path.in our study, we found that The role of families in the rehabilitation process of hearing-impaired children has not been fully played, and the rehabilitation of hearing-impaired children urgently needs to be extended from schools and rehabilitation institutions to families, so as to form a more unified and comprehensive rehabilitation system.

At present, special education and rehabilitation knowledge, as professional knowledge, is mainly concentrated by doctors, experts in rehabilitation institutions, teachers of special education and other groups. A study observed that parents struggle to communicate with their hearing impaired children hence some parents end up using gestures, facial expression, pointing, touching and other manual signs that are not recognised in trying to communicate with their children ${ }^{15}$.

Most parents of special children have sporadic and insufficient special education knowledge, leading to a serious shortage of educational effectiveness. They can not correctly understand the physical and mental development characteristics of special children, can not objectively look at the differences of children, can not systematically plan the education of children, and there are unreasonable expectations for children. Furthermore, parents' levels of education and economic status have a significant effect on their parents' needs ${ }^{16}$.

The survey data also show that parents generally have a low grasp of the rehabilitation and education knowledge of hearing-impaired children, but they have a strong willingness to understand and learn about the rehabilitation and education knowledge of hearing-impaired children. Therefore, we propose to combine online and offline classes to provide effective channels for parents to learn these knowledge.

Different hearing-impaired children have their own characteristics such as family environment and rehabilitation progress. If only relying on universal and non-systematic rehabilitation techniques, it is difficult to ensure that every child can achieve a better rehabilitation effect. In order to improve the adaptability of the hearing-impaired children with their own conditions and rehabilitation methods, we put forward the "personalized family rehabilitation guidance ", as a new focus on improving the rehabilitation effect in the family perspective. This guidance puts forward more effective solutions for hearing impaired 
children's hearing recovery, language development, mental health and comprehensive rehabilitation in the future by means of professional assessment, personalized intervention and dynamic tracking.

Many parents have a one-sided cognition of the psychological development rules of special children, and they still can't deal with emergencies effectively. Moreover, due to various obstacles in the society and work, online and offline large-scale lectures may not meet the learning needs of some parents. In this era of new media, a lot of high-quality short videos are booming according to the needs of the society. As a common, streamlined and efficient publicity mode, short videos are favored by many people.

Language rehabilitation teaching of hearing impaired children is much different from that of normal people, the relevant curriculum software is still in the experimental stage, and the clinical and non-clinical applications are relatively limited. For personalized family rehabilitation mode, the intervention of the assisted mode of online speech rehabilitation APP can provide a more convenient technical choice for their rehabilitation training, while the assistance of online supporting courses will also facilitate the transition from special education to general education for hearing-impaired children.

\section{Conclusion}

Rehabilitation programs should dedicate more attention to informing parents about the impact of family factor on children's rehabilitation, especially on children's psychological rehabilitation.

In view of how to play the family function to help hearing-impaired children recover, we put forward a series of measures with solid theoretical basis in this study. In addition, a new rehabilitation modeCBM(cognition-behaviour-mentality)for hearing-impaired children was established to promote the family efficacy and activate the comprehensive rehabilitation of hearing-impaired children(Fig. 7).

\section{Declarations}

\section{Data Availability}

Data is available by request from the authors.

\section{Author contributions}

M.Y. and H.X. contributed to the conception of the study. M.Y. and Q.C. performed the data analyses and wrote the main manuscript text. S.Y. and Q.C. assisted with data collection. H.X. supervised the research. All authors intellectually contributed to this manuscript and reviewed the manuscript.

\section{References}

1 Lieu, J. E. C., Kenna, M., Anne, S. \& Davidson, L. Hearing Loss in Children: A Review. Jama 324, 21952205, doi:10.1001/jama.2020.17647 (2020). 
2 Soares, A. D., Goulart, B. N. \& Chiari, B. M. Narrative competence among hearing-impaired and normalhearing children: analytical cross-sectional study. Sao Paulo Med J 128, 284-288, doi:10.1590/s151631802010000500008 (2010).

3 Ketelaar, L., Wiefferink, C. H., Frijns, J. H. M. \& Rieffe, C. Children With Cochlear Implants and Their Parents: Relations Between Parenting Style and Children's Social-Emotional Functioning. Ear Hear 38, 321-331, doi:10.1097/aud.0000000000000387 (2017).

4 Sayed, S. Z., Mounir, S. M., Mohamed, A. A., Nabil, A. M. \& Hassan, M. H. Assessment of psychological disorders in Egyptian children with hearing impairment. Sudan J Paediatr 18, 25-32, doi:10.24911/sjp.106-1531768895 (2018).

5 Stein, L., Clark, S. \& Kraus, N. The hearing-impaired infant: patterns of identification and habilitation. Ear Hear 4, 232-236, doi:10.1097/00003446-198309000-00002 (1983).

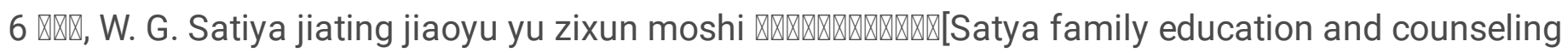
model]. Jiao Yu Ping Lun, 165-168 (2010).

7 Furlong, L., Erickson, S. \& Morris, M. E. Computer-based speech therapy for childhood speech sound disorders. J Commun Disord 68, 50-69, doi:10.1016/j.jcomdis.2017.06.007 (2017).

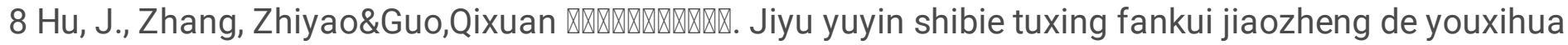

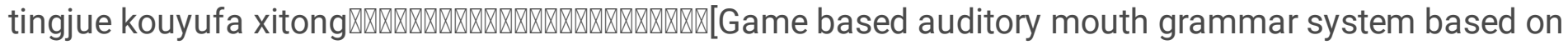
speech recognition and graph feedback correction]. CN111798855A (2020).

9 Gross, D., Fogg, L. \& Tucker, S. The efficacy of parent training for promoting positive parent-toddler relationships. Res Nurs Health 18, 489-499, doi:10.1002/nur.4770180605 (1995).

10 North, J. Auditory-Verbal Therapy: for young children with hearing loss and their families, and the practitioners who guide them. Deafness \& Education International 19 (2017).

11 Rhoades. Research Outcomes of Auditory-Verbal Intervention: Is the Approach Justified? Deafness \& Education International 8 (2006).

12 Binos, P., Nirgianaki, E. \& Psillas, G. How Effective Is Auditory-Verbal Therapy (AVT) for Building Language Development of Children with Cochlear Implants? A Systematic Review. Life (Basel) 11, doi:10.3390/life11030239 (2021).

13 Shauli, S. \& Baram-Tsabari, A. The usefulness of science knowledge for parents of hearing-impaired children. Public Underst Sci 28, 19-37, doi:10.1177/0963662518772503 (2019).

14 Erbasi, E., Scarinci, N., Hickson, L. \& Ching, T. Y. C. Parental involvement in the care and intervention of children with hearing loss. Int J Audio/ 57, S15-s26, doi:10.1080/14992027.2016.1220679 (2018). 
15 Mbaluka, Kurebwa \& Wadesango. Parents | L Mode of Communication with Their Hearing Impaired Children in Gweru Urban. Journal of Human Ecology 42 (2013).

16 Eyalati, N., Jafari, Z., Ashayeri, H., Salehi, M. \& Kamali, M. Effects of parental education level and economic status on the needs of families of hearing-impaired children in the aural rehabilitation program. Iran J Otorhinolaryngo/ 25, 41-48 (2013).

\section{Figures}

\section{Figure 1}

Gender ratio.

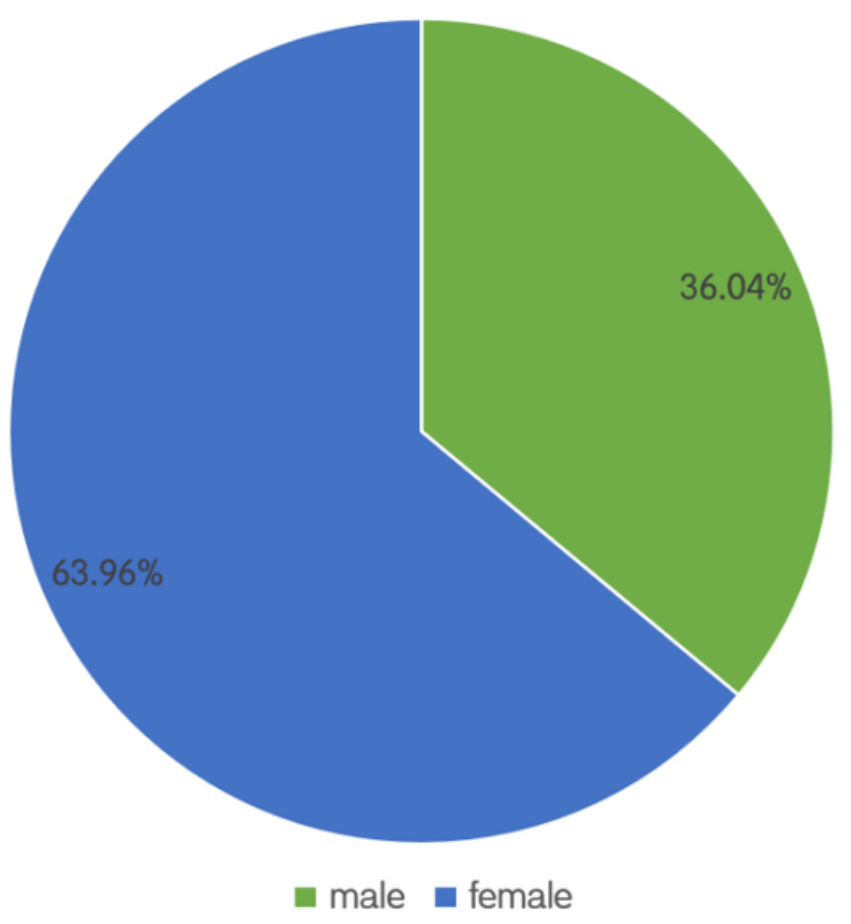

\section{Figure 1}

See image above for figure legend 
Figure 2

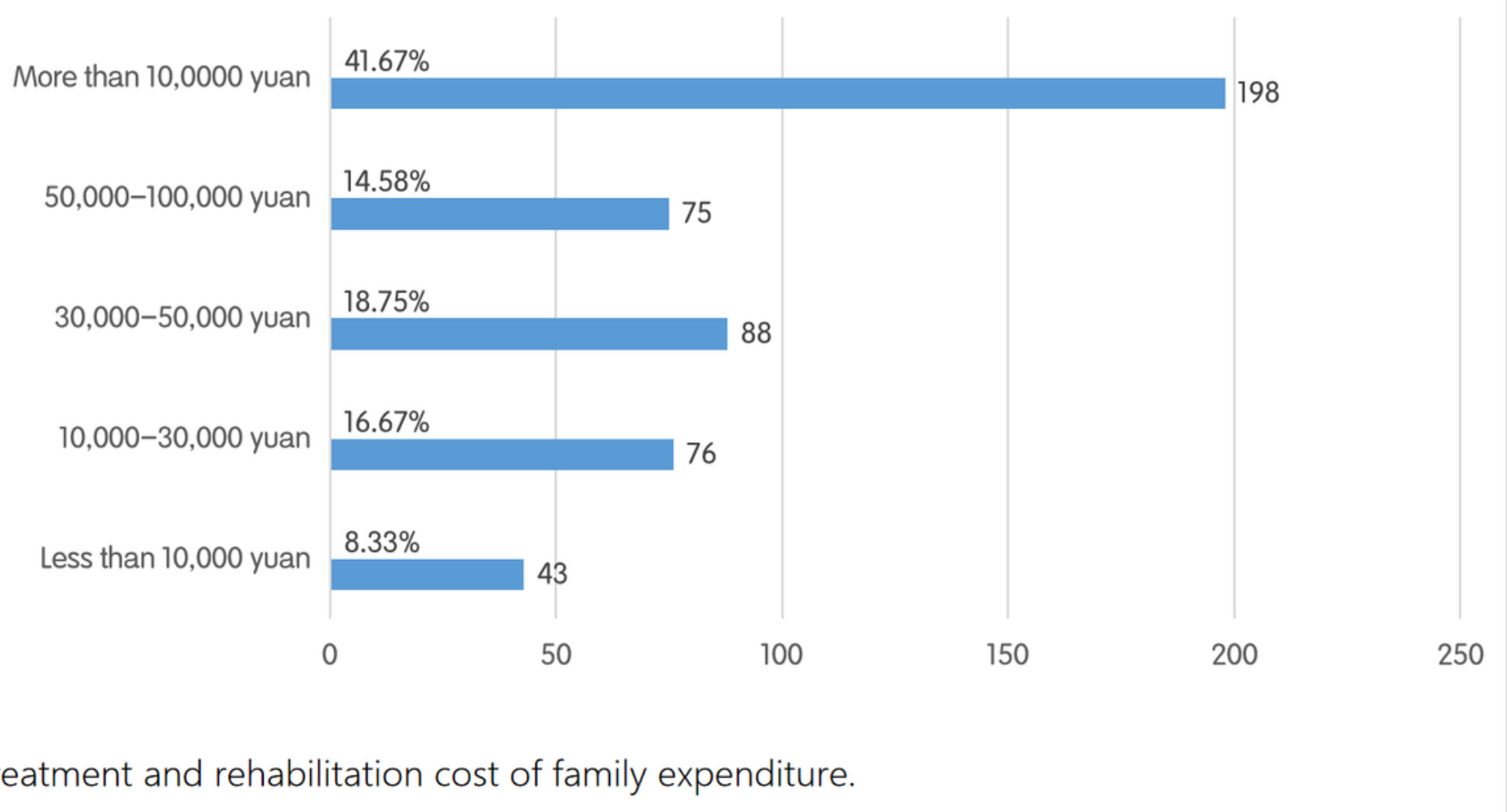

Figure 2

See image above for figure legend 


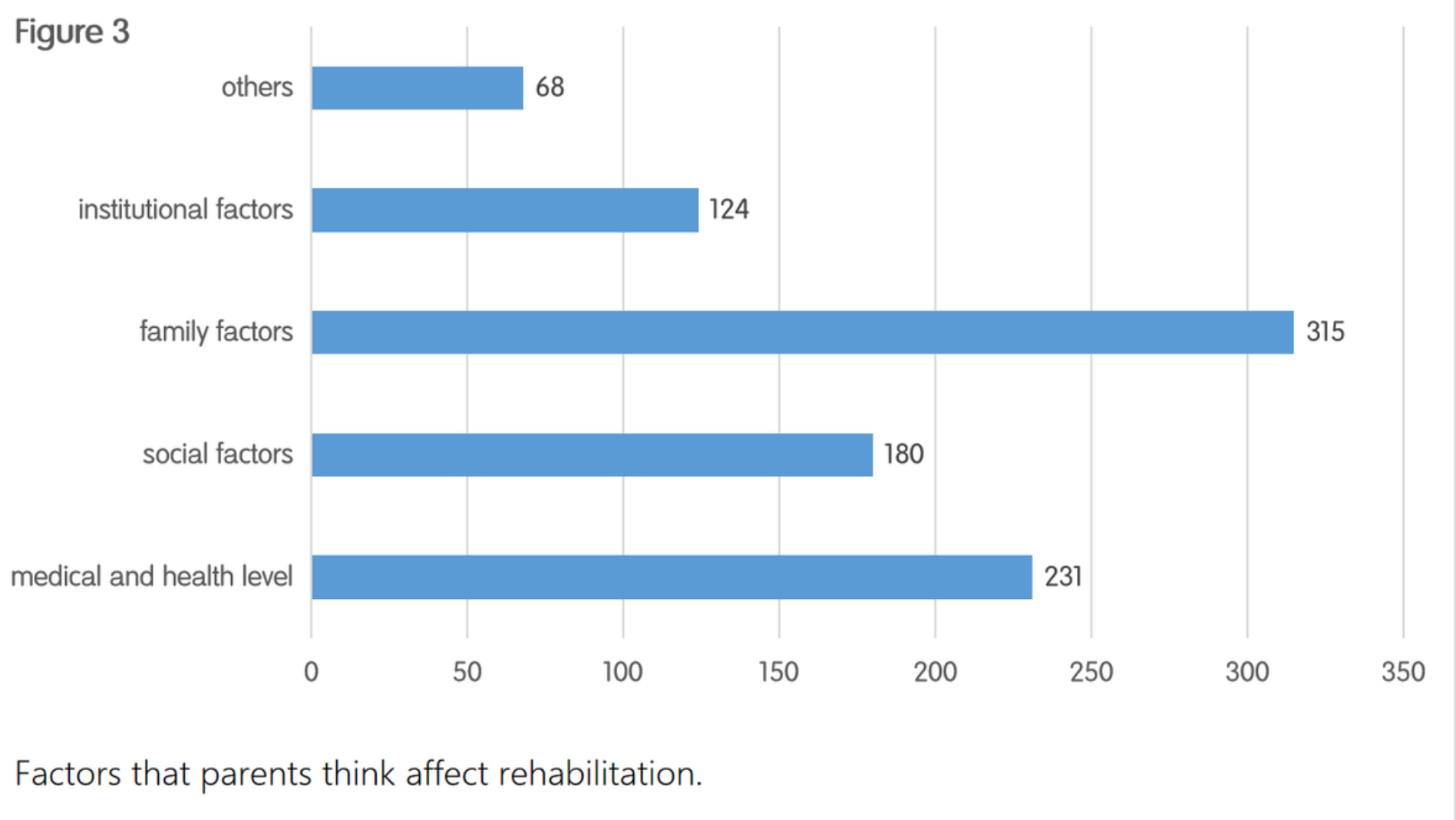

\section{Figure 3}

See image above for figure legend 


\section{Figure 4}

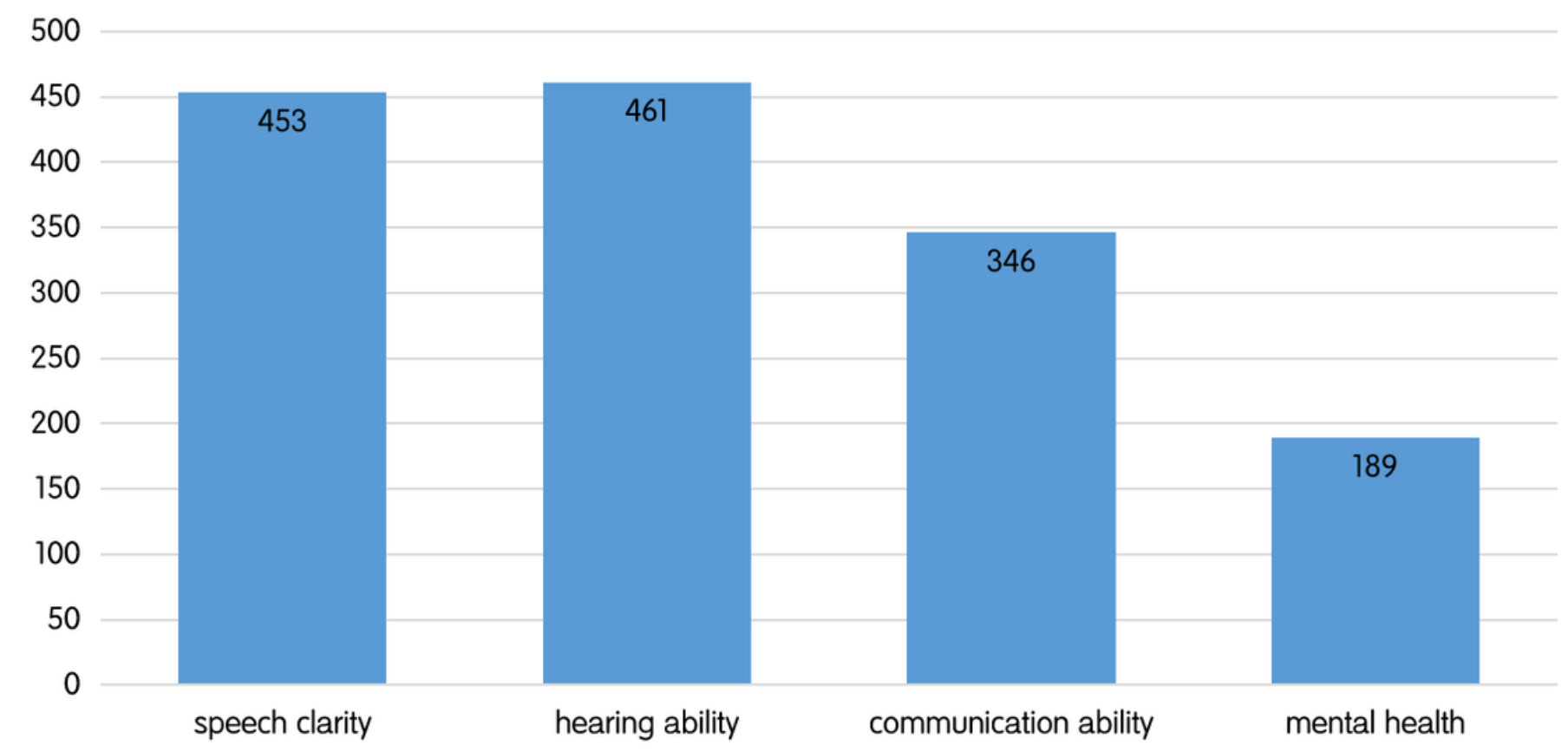

Parents' views on the content of rehabilitation treatment.

\section{Figure 4}

See image above for figure legend 


\section{Figure 5}

600

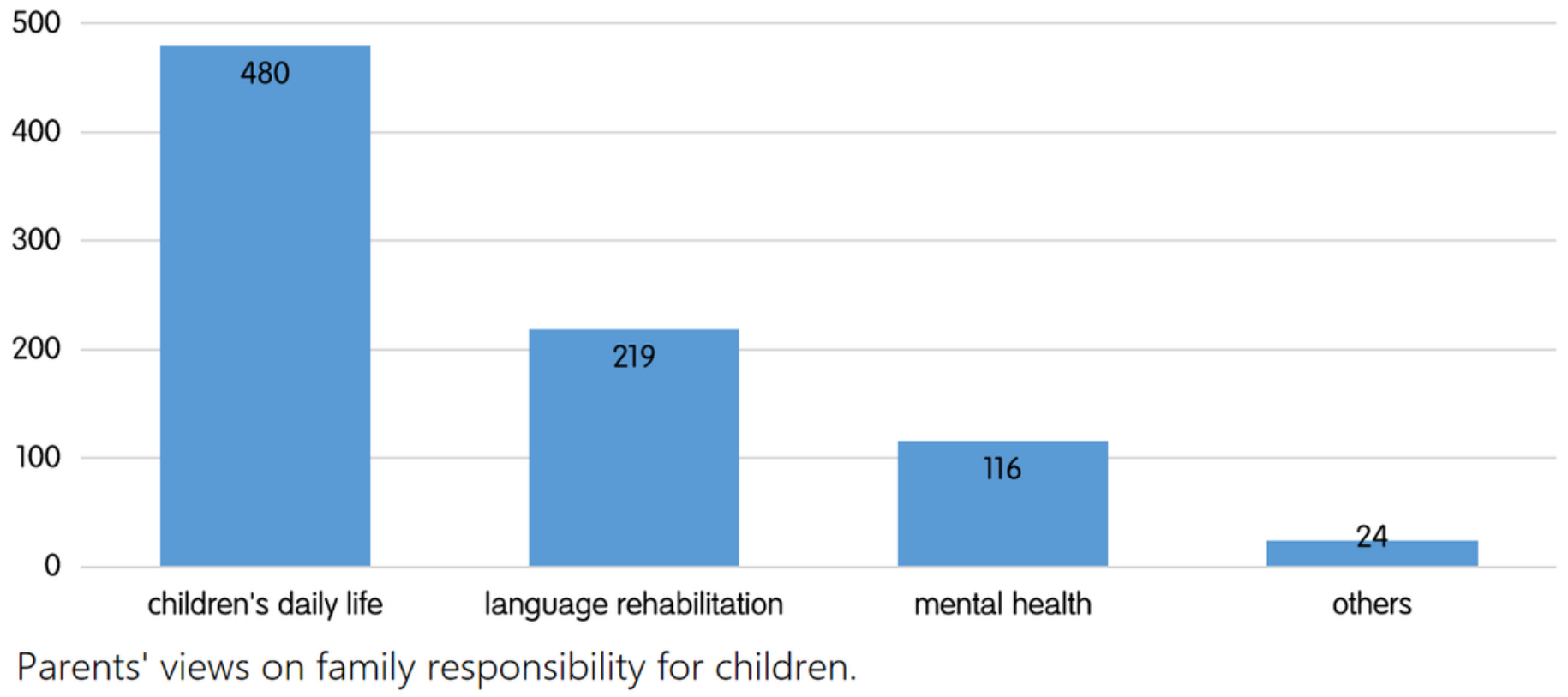

\section{Figure 5}

See image above for figure legend 
Figure 6

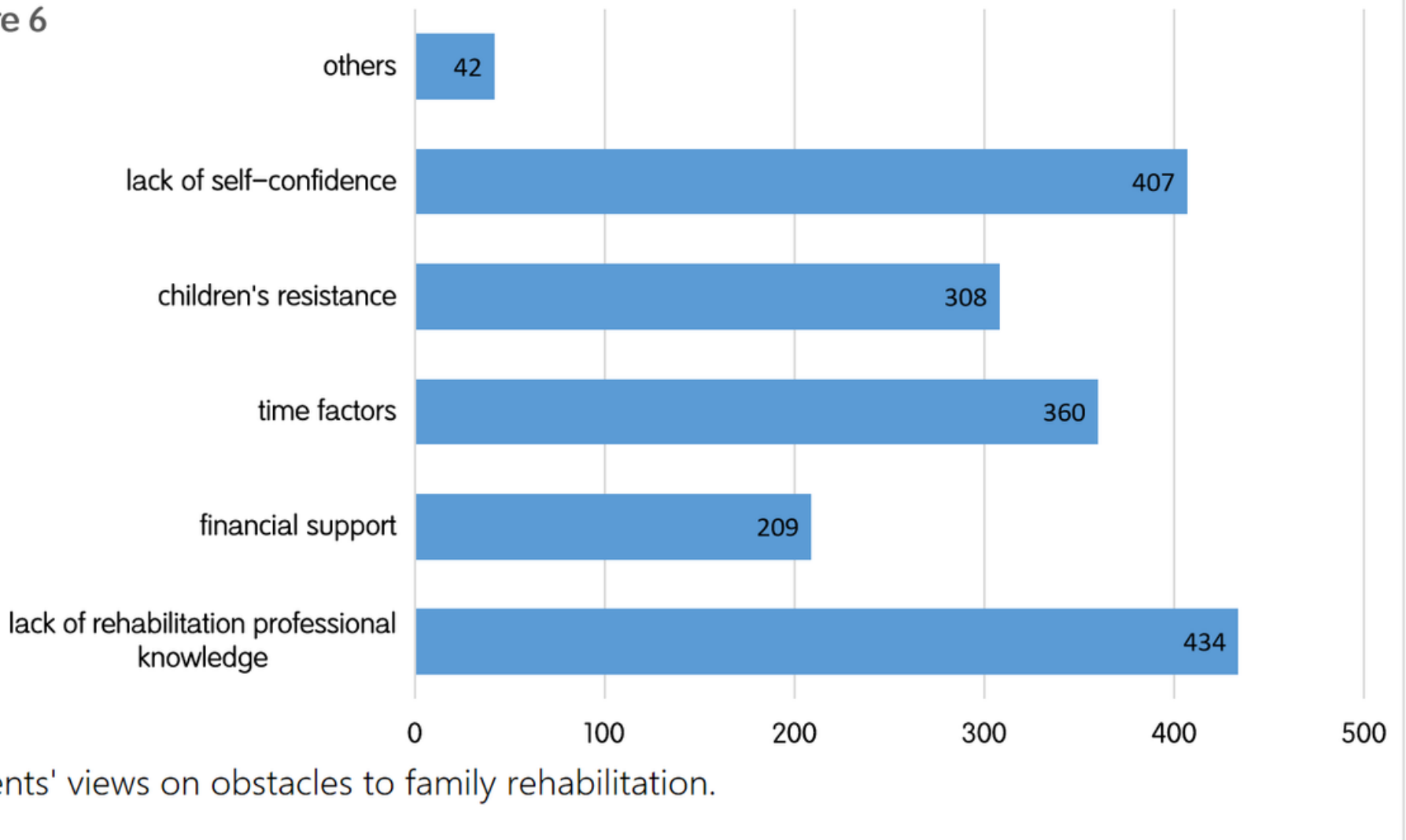

Figure 6

See image above for figure legend

Figure7

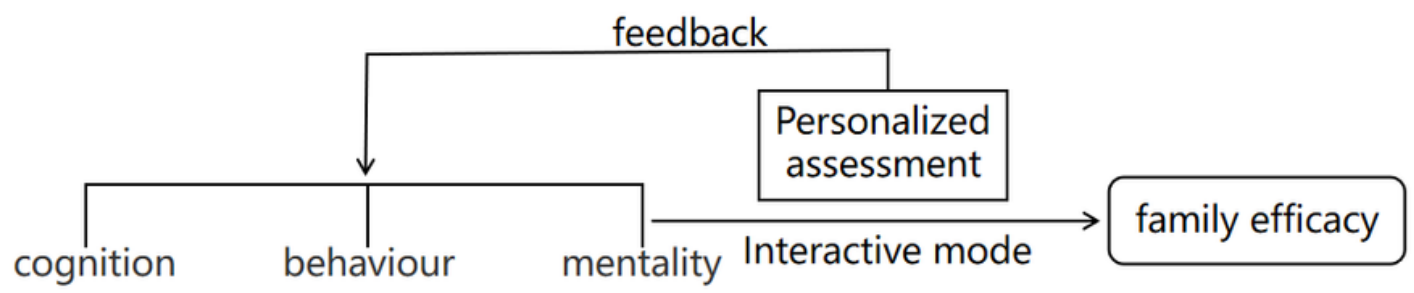

CBM ( cognition-behaviour-mentality ) mode

\section{Figure 7}

See image above for figure legend 